Article

\title{
Evaluation of Commercial Wheat Cultivars for Canopy Architecture, Early Vigour, Weed Suppression, and Yield
}

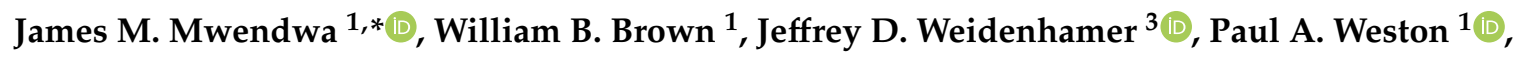 \\ Jane C. Quinn ${ }^{1}$ (D), Hanwen $W^{1,2}$ and Leslie A. Weston ${ }^{1}$ (D) \\ 1 Graham Centre for Agricultural Innovation, Charles Sturt University, Wagga Wagga, NSW 2650, Australia; \\ plantinteractions@csu.edu.au (W.B.B.); pweston@csu.edu.au (P.A.W.); jquinn@csu.edu.au (J.C.Q.); \\ hanwen.wu@dpi.nsw.gov.au (H.W.); leweston@csu.edu.au (L.A.W.) \\ 2 Department of Primary Industries, Plant Biosecurity, Wagga Wagga, NSW 2650, Australia \\ 3 Department of Chemistry, Geology and Physics, Ashland University, Ashland, OH 44805, USA; \\ JWEIDEN@ashland.edu \\ * Correspondence: jmwendwa@csu.edu.au
}

Received: 16 April 2020; Accepted: 7 July 2020; Published: 9 July 2020

check for updates

\begin{abstract}
Herbicide resistance in weeds restricts control options, thereby escalating economic loss and threatening agricultural sustainability in cereal production. Field evaluation of the crop performance, competitive traits, and consequent weed suppressive potential of 13 commercial winter wheat (Triticum aestivum L.) cultivars was performed in central NSW Australia with a focus on the evaluation and modelling of above-ground interactions. In 2015 and 2016, replicated field trials were established with genetically diverse commercial wheat genotypes under moderate to low rainfall conditions in Wagga Wagga $(572 \mathrm{~mm})$ and Condobolin $(437 \mathrm{~mm})$ New South Wales, respectively. The heritage cultivar Federation and a commercial cultivar of winter cereal rye (Secale cereale L.) were included as known weed-suppressive controls. Crop and weed growth, as well as early vigour, leaf area index, and photosynthetically active radiation, were monitored at various crop phenological stages including early growth, vegetative, flowering, grain fill, and harvest. Significant differences between wheat cultivar and location were observed for crop biomass, early vigour, leaf area index, weed number, weed biomass, canopy architecture, and yield in both 2015 and 2016. Differences in weed establishment were largely impacted first by rainfall and season and secondly by crop architecture (i.e., height, size, canopy) and phenology (i.e., growth stages). Early vigour and early canopy closure were instrumental in suppressing weed establishment and growth. Cultivar performance and competition with weeds were also clearly influenced by both environmental factors and genotype, as evidenced by differences in early cultivar performance, yield, and weed suppression by season and location. Specifically, Federation, Condo, and Janz wheat cultivars were superior performers in terms of weed suppression in both locations and years; however, Federation produced up to 55\% lower yield than recently introduced cultivars. Partial least squares (PLS) regression was performed to develop a predictive linear model for weed competition in commercial wheat cultivars based on weed dry biomass as the response variable and selected aboveground crop canopy traits as predictors. In 2015, the model differed in accordance with crop growth stage, but the impact of predictors on weed biomass at both locations was not significant. In 2016, under local above average rainfall conditions, the model showed a significant negative correlation $(p<0.001)$ of most predictors on weed biomass ( $r^{2}=0.51$ at Condobolin, $r^{2}=0.62$ at Wagga Wagga), suggesting the most influential factors in reducing weed numbers and establishment as crop vigour, biomass, and height. Our results indicate the establishment of competitive wheat cultivars in the absence of post-emergent herbicides resulted in a two to five-fold increased weed suppression over less suppressive genotypes, without significant yield penalties. Therefore, cultivar choice constitutes a cost-effective and sustainable weed management tool, particularly when weed pressure is significant.
\end{abstract}


Keywords: weed suppression; integrated weed management; canopy light interception; phenology; leaf morphology; crop competition

\section{Introduction}

Weeds are a persistent problem in cereal crops, increasing production costs while reducing crop yields [1]. Worldwide, yield losses of approximately $34 \%$ are caused by weeds among the major food crops and are typically higher than losses due to other crop pests [2]. Herbicides are the most widely used tools to manage weeds in commercial crops, but weeds have now evolved resistance to 23 of the 26 known herbicide sites of action and to 163 different herbicides across the globe [3], thereby limiting options for chemical control, escalating economic losses and threatening agricultural sustainability [1]. This threat comes at a time when global population growth necessitates greater agricultural productivity for food sustainability, and environmental concerns have resulted in significant restrictions on the use of many herbicides.

In Australia, herbicide resistance in both grasses and broadleaf weeds is on the rise, with resistance to multiple herbicides reported for an increasing number of arable weeds [4]. Llewelyn et al. [5] estimated that the cost of additional herbicides due to herbicide resistance was AUD 187 million on top of the costs of using extra integrated weed management practices. They also reported the overall cost of weeds to Australian grain growers as AUD 3.3 billion annually, which equates to AUD 146/ha in expenditure and yield losses of ca. 2.76 million tonnes of grain annually. Therefore, crops that significantly reduce weed growth are an attractive option, because they offer a potentially sustainable strategy with no additional in-crop weed management costs [6].

Both above and below-ground crop competition have been shown to contribute to crop interference with weed growth under controlled and field growth conditions. The combined effects of both typically determine the total competitive ability of a crop cultivar. Recent research has been undertaken to improve both competitive and allelopathic (chemical interference) potential simultaneously to achieve maximum gains in crop weed suppression $[7,8]$. Competitive wheat genotypes have been demonstrated to result in up to $50 \%$ reductions in weed numbers and herbicide applications [9] due to the above-ground suppression of weeds. In addition, Milan et al. [10] demonstrated that hybrid and conventional wheat cultivars were competitive in multiple years of field studies. However, others have reported that certain heritage cultivars suppressed significantly greater weed biomass at harvest compared to most modern cultivars [11].

Integrated weed management (IWM) practices have focused on the use of enhanced above-ground crop competitive ability using competitive cultivars in combination with chemical control methods and cultural practices such as increased seeding rates, narrow row spacing, altered row orientation, crop rotation, and delayed seeding [4,12], while maintaining acceptable yields and suppressing weed populations [6,8]. The selection of morphological traits that enhance early crop vigour, including leaf size, light interception, plant height at tillering [13], as well as grain yield in weedy conditions, and grain yield tolerance $[14,15]$, are important factors to consider in breeding programs when improving the competitive ability of modern wheats without compromising yield $[6,16]$.

Early vigour of a cultivar has been shown previously to be related to crop establishment and the rate at which above-ground biomass is produced and has been correlated with morphological leaf traits such as leaf area and light interception in the earliest phases of growth [17]. Christensen [18] also observed that more rapidly developing cultivars of spring barley were weed suppressive, while Coleman et al. [19] reported that the rapid development of leaf area improved the weed competitive ability of wheat. Seavers and Wright [20] reported that the competitive ability of wheat, oat, and barley cultivars against Galium aparine L. was associated with greater leaf area and height, resistance to loss of tillers under competition pressure, and a faster rate of canopy development. In wheat, traits relating to leaf 
size, specific leaf area, and rate of production vary between cultivars but have been linked to higher suppressive ability $[19,21]$.

Crop competitive ability can be separated into two components: (1) competitive effect or weed-suppressive ability, i.e., the capacity of the crop to reduce weed growth and reproductive success through interference, and (2) the competitive response or weed tolerance; i.e., the ability of the crop to mature and yield despite the presence of weeds $[14,22,23]$. Therefore, a crop's ability to both suppress weed growth and tolerate weed competition is a key consideration when taking an agroecological approach to weed management [13]. The application of integrated weed control strategies [24] combined with increased precision with regard to agronomic factors including crop seeding rate or row spacing for enhancing competitive crop ability in different environments $[25,26]$ is required to inform the final cultivar choice. In this study, field experiments were performed using standard row spacings and seeding rates to assess the competitive traits of commercial Australian winter wheat cultivars, with a focus on above-ground interactions. Specific crop morphological traits were evaluated for their association with weed suppression in a two-year study over two locations with the objective of evaluating genotypically diverse cultivars for enhanced weed suppression and yield tolerance in the low to moderate rainfall zone in southern Australia.

\section{Materials and Methods}

\subsection{Site Description and Experimental Design}

In 2015 and 2016, replicated wheat field trials were sown at two locations in moderate to low rainfall zones at Wagga Wagga $(572 \mathrm{~mm})$ and Condobolin $(449 \mathrm{~mm}) \mathrm{NSW}$, respectively. In both years, 13 wheat cultivars representing four major genetic backgrounds of winter and spring wheat commercially grown in Australia were selected for evaluation, plus Grazer, which is a cultivar of winter cereal rye (Secale cereale L.) as a positive suppressive control (Table 1), resulting in a total of 14 treatments. The 14 plots were seeded with six replications in a randomised complete block design

Treatments included wheat cultivars with both short and moderate time to maturity along with two grazing winter wheat cultivars, Whistler and Wedgetail (Table 1). Other notable cultivars included the recently released cultivar Trojan, as well as Federation, which is an older heritage cultivar that was bred and released in 1901 and widely used until 1970. Federation is considered to be both early maturing and drought resistant and was included for comparison of its inherent weed-suppressive abilities and upright growth habit with more recent releases. Experimental sites were established in close proximity at each location in both 2015 and 2016 following a canola crop at each site.

At Wagga Wagga, field trials were conducted on fine red clay loam kandosols, surface pH 6.4, previously planted commercially for the production of cereals, canola, and/or lucerne (Medicago sativa L.). At Condobolin, soils were predominantly red gradational, and red-brown earth sodosols with surface $\mathrm{pH} 7.0$ and were previously rotated among canola, cereals, and pasture legume crops. Both soils were maintained using standard commercial practices to reduce weed populations [27] such as preand post-chemical control.

\subsection{Crop Establishment}

At sowing, replicated composite soil samples $(10 \mathrm{~cm}$ circular core by $5 \mathrm{~cm}$ depth) were taken from each replicate block $(12 \times 28 \mathrm{~m})$ to evaluate the weed species in the seedbank at experimental initiation as suggested by Menalled and Schonbeck [28]. Fifteen samples were taken every two meters along two diagonal transects in each replicate $\left(336 \mathrm{~m}^{2}\right)$, and 30 samples were bulked. In the glasshouse, the bulked samples were spread over the soil media surface in trays and watered regularly for evaluation of the existing weed seedbank at each location, including both winter and summer annuals. Then, weed seedbanks were evaluated separately by species for six months with continued flushes of seedling emergence recorded and consequently removed to allow for further establishment. Weed species densities were calculated based on the formula applied by Nkoa et al. [29]. 
Density $=$ total number of weed species in a tray $\div$ total area of the replicate $\times 100$

All crops were established with seed generated in Wagga Wagga harvested from the previous trial season. This potentially eliminated cultivar variation due to seed variability resulting from production at different sites [27,30]. At Condobolin, the crop was sown on 15 and 17 May at $33 \mathrm{~cm}$ spacing, which is typical for drier soils, while at Wagga Wagga, the crop was sown on 22 and 14 May at $25 \mathrm{~cm}$ spacing for 2015 and 2016, respectively, due to soil moisture differences encountered among the regions. Cultivars were established at equal plant density (target population of 120 plants $/ \mathrm{m}^{2}$ ) in each trial by sowing seed lots adjusted for seed weight per cultivar and germination rate. A total of 200 seeds of each cultivar were weighed, and the weight was multiplied by five to determine the seed weight/ 1000 . For a specific target plant population, the following calculation was performed for each cultivar to determine the sowing rate [27].

Sowing rate $(\mathrm{kg} / \mathrm{ha})=($ Seed weight $/ 1000(\mathrm{~g}) \times$ Proposed target plant population (plants $\left.\left./ \mathrm{m}^{2}\right) \times 100\right) \div($ Expected Establishment $\% \times$ Actual germination percentage $)$

Plots were planted using a calibrated disc cone seeder (Kimseed Australia Pty Ltd, Wangara, Australia) with a 22 and $30 \mathrm{~cm}$ row spacing and 25 and $33 \mathrm{~cm}$ in-row spacing between plants respectively at Wagga Wagga and Condobolin. Seeds were sown together (in-row) with granulated fertiliser; diammonium phosphate (DAP) (analysis 17.1\% N, 20.0\% P; Incitec Pivot Fertilisers, Melbourne, Australia) was applied at $70 \mathrm{~kg} / \mathrm{ha}$. DAP was treated with $400 \mathrm{ml} /$ ha Flutriafol (Intake®Hiload Gold $200 \mathrm{~g} /$ ha Flutriafol, Nufarm Australia, Melbourne, Australia). Before sowing, all the established weeds were controlled with glyphosate (Weedmaster®DST®470 g/L Glyphosate, Nufarm Australia, Melbourne, Australia) at $960 \mathrm{~g} / \mathrm{ha}$. Individual plots measured $2 \times 12 \mathrm{~m}$ and were trimmed to $2 \times 10 \mathrm{~m}$ after crop establishment.

\subsection{Crop Assessments and Data Collection}

Data collection was performed at each location at critical plant developmental stages of crop establishment including stem elongation, flowering, and maturity. Data were collected each year on various crop morphological characteristics shown to be previously associated with cereal crop competitiveness, including leaf size, early vigour, and crop canopy closure. A light ceptometer (AccuPAR LP-80 Ceptometer, Decagon Devices@, Pullman, Washington, United States) was used to measure PAR (photosynthetically active radiation $\mu$ mols $\mathrm{m}^{2} \mathrm{~s}$ ) both above and below the crop canopy), light interception (\%), and leaf area index ( $\mathrm{LAI} \mathrm{m}^{2}$ ). Leaf area index and light interception (\%) below the crop canopy were calculated from the above and below canopy PAR readings. All measurements were made between $11 \mathrm{~h}$ and $14 \mathrm{~h}$ (solar noon at $13 \mathrm{~h}$ ).

NDVI (normalised difference vegetative index) readings (GreenSeeker $§ 505$ handheld sensor and Trimble $囚 R e c o n$ PDA, NTech Industries Inc. Sunnyvale, California, United States) were obtained (at 1 to $1.5 \mathrm{~m}$ above ground) to monitor canopy closure and estimate crop biomass production. NDVI is preferable for global vegetation monitoring, since it compensates for changes in lighting conditions, surface slope, exposure, and other external factors. Low NDVI values indicate moisture-stressed or sparse vegetation, and higher values indicate a healthy and dense of green vegetation. NDVI was calculated in accordance with the formula:

$$
\text { NDVI }=\text { NIR-RED/ NIR + RED }
$$

where NIR is reflection in the near-infrared spectrum and RED is reflection in the red range of the spectrum. 
Other assessments included crop biomass and weed biomass in crop, visual vigour ratings $(0=$ poor, no stand, $5=$ crop with more than $50 \%$ open canopy space, $10=$ high vigour, closed canopy $)$ based on crop growth and biomass accumulation over time, specifically ground cover leading to canopy closure (a 10 would be recorded for an extremely vigorous crop with closed canopy in contrast to a less vigorous crop with open canopy allowing light to reach the soil surface). Post-harvest weed suppression visual ratings were also performed $(0=$ weeds absent, $5=$ crop and weeds at 50:50 ratio, $10=$ weeds dominate, no crop) [31]. Time units in all results are expressed as days after crop emergence (DAE).

Above-ground crop biomass, total weed numbers (overall and per significant individual species), and weed biomass were measured in two $50 \times 50 \mathrm{~cm}$ quadrats per plot in all 6 replicates at four critical growth stages: early growth (30-40 days following establishment), vegetative growth (60-70 days following establishment), flowering, and crop harvest. Biomass was obtained by cutting plant material at the soil surface and weighing after drying at $40{ }^{\circ} \mathrm{C}$ for 5 days in a forced-air oven. Weed counts were monitored in-crop and after harvest by counting identified weeds in two $50 \times 50 \mathrm{~cm}$ quadrats per plot. To increase the robustness of the data collected to estimate both weed numbers and biomass, we obtained an appropriate number of sub-samples $(6 \times 2$ replicates $=12$ subsamples $)$, which were collected in each cultivar treatment. Sub-sampling in six replications has proven useful in past experimentation at both locations given the inherent variability of weed populations in field conditions. Grain harvest was performed at crop maturity before 15 December in each year and location, using a small plot harvester (plot harvest area $=18 \mathrm{~m}^{2}$ ). The yield was measured as harvested cereal grain in $\mathrm{t} / \mathrm{ha}$. Due to the impact of unusually high and low daily temperatures at Condobolin in 2015 on crop yield, the mean maximum temperature for both years are presented together with yield data in Section 3.5.

\subsection{Data Analysis}

Trial design, randomisation, and data analyses were performed using Agricultural Research Manager (ARM) version 9.0 (Gylling Data Management Inc. 2014). Comprehensive statistical analysis of selected data sets was later performed using GenStat [32] for ANOVA and MANOVA REML (residual/restricted maximum likelihood) or regression model with means separated using Least Significant Difference (LSD, 0.05 confidence level). The competitive effectiveness of each cultivar in terms of weed suppression was calculated using the following equation based on the least weed suppressive cultivar in the same year and location.

$$
\mathrm{C}_{\mathrm{e}} \mathrm{W}_{\mathrm{s}}=\left(\mathrm{C}_{\mathrm{l}} \mathrm{W}_{\mathrm{b}}-\mathrm{C}_{\mathrm{t}} \mathrm{W}_{\mathrm{b}}\right) \div \mathrm{C}_{\mathrm{l}} \mathrm{W}_{\mathrm{b}} \times 100
$$

where $\mathrm{C}_{\mathrm{e}} \mathrm{W}_{\mathrm{s}}$ is the cultivar effectiveness in weed suppression, $\mathrm{C}_{1} \mathrm{~W}_{\mathrm{b}}$ is the value of weed dry biomass for the cultivar with the least weed biomass in the year and location, and $C_{t} W_{b}$ is the value of weed dry biomass for the cultivar.

Data generated in this study investigated multiple interactions both at a plant and environmental level. In order to analyse this complex dataset and due to its display of multicollinearity (e.g., PAR, LAI, and height), a model was generated that utilised partial least squares (PLS) regression or (PLS-R) as the statistical model. PLS regression is a technique that reduces the predictors to a smaller set of uncorrelated components and performs least squares regression on these components instead of on the original data. This analysis is particularly useful when predictors are highly collinear or when there are more predictors than observations [33]. The interrelatedness of plant characteristics associated with canopy structure and weed competitiveness in grain crops (i.e., plant height, early canopy closure, LAI, vertical leaf orientation, rapid biomass accumulation at the early crop growth stage, high shoot dry matter, large root biomass and root volume [34]) makes PLS regression analysis particularly well-suited to characterise relationships between crop plant characteristics and weed suppression. 
Statistical analysis modelling of the data was performed by linear and partial least squares (PLS) regression for randomised experiments with four replicates using XLSTAT (Addinsoft, New York, USA). Dry weed biomass was used as the dependent variable (or variable to model), while the quantitative explanatory variables included crop biomass, PAR light interception expressed as percentage of PAR light intercepted by crop canopy at the sampling time, leaf area index, visual vigour ratings, and NDVI, taking into account the time of sampling and crop growth stage. PLS results are presented on the variable importance in model projection (VIP) charts (one bar chart per component); a border line is plotted to identify the VIPs that are greater than 0.8 and above. These thresholds allow identification of the variables that are moderately $(0.8<$ VIP $<1)$ or highly influential (VIP $>1)$ [35]. The VIP score first published by Wold and others in 1993 measures the explicative power of predictor variables with respect to the response variable based on the PLS-R. The VIP score of variable $j$ is calculated by the equation below:

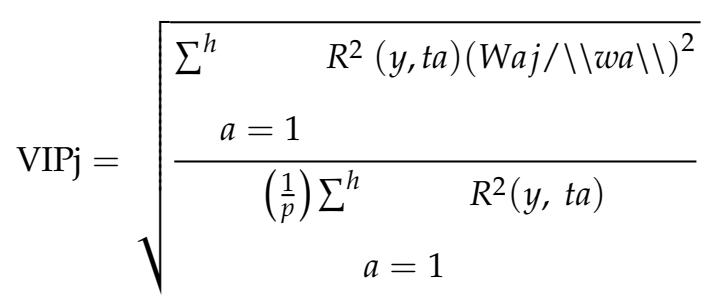

where Waj is weight of the jth predictor variable in component a and $R^{2}(y, t a)$ is a fraction of variance in $y$ explained by the component a. The variable with a higher VIP score indicates that it is more relevant to predict the response variable [35]. 
Table 1. Wheat cultivars and commercial use for field trials performed in Condobolin and Wagga Wagga, NSW in 2015 and 2016.

\begin{tabular}{|c|c|c|c|c|}
\hline Cultivar & Breeder & Year of Release & Main Use & Growth Characteristics \\
\hline Condo & $\mathrm{AGT}^{1}$ & 2014 & grain & $\begin{array}{l}\text { Early maturity adapted to low-medium rainfall areas. Similar in maturity to Livingston. } \\
\text { Has consistently yielded well in low-medium rainfall environments. A tall plant type with medium } \\
\text { straw strength. Moderately tolerant of acid soils. }\end{array}$ \\
\hline Corack & AGT & 2011 & grain & $\begin{array}{l}\text { Derived from Wyalkatchem, an early-maturing cultivar with high straw strength. Could be suitable for } \\
\text { a wheat-on-wheat situation, low rainfall environments, or late sowings. Highly tolerant of acid soils. }\end{array}$ \\
\hline Espada & AGT & 2008 & grain & $\begin{array}{l}\text { Mid-season maturity. Best performance in medium to high yield potential areas. Good seedling vigour. } \\
\text { Produces large grain. }\end{array}$ \\
\hline Federation $^{2}$ & William Farrer & 1901 & grain & $\begin{array}{l}\text { The first specifically Australian variety that is both rust and drought resistant. Early maturing, } \\
\text { high yielding, and drought tolerant with strong straw. Awnless and broad adaptation. }\end{array}$ \\
\hline Grazer (Cereal rye) ${ }^{3}$ & & & dual purpose & $\begin{array}{l}\text { Performs well on lighter soils. Rapid growth with early vigour and grazing possible four weeks after } \\
\text { emergence if tillering and the secondary root system development has occurred to anchor the plant. }\end{array}$ \\
\hline Gregory & EGA $^{4}$ & 2004 & grain & $\begin{array}{l}\text { Excellent yield potential in early to mid-season sowings in northern and southern Australia. Medium to } \\
\text { slow maturity. }\end{array}$ \\
\hline Janz CL & AGT & 1989 & grain & $\begin{array}{l}\text { Widely adapted main season Clearfield®(BASF, Germany) variety. Moderate seedling vigour. } \\
\text { Medium-strong straw strength, with good lodging and shattering resistance. }\end{array}$ \\
\hline Livingston & AGT & 2008 & grain & $\begin{array}{l}\text { Early maturing cultivar. Livingston is derived from a cross involving Sunvale and was released as } \\
\text { a higher-yielding alternative for Ventura in areas that are not constrained by acid soils. }\end{array}$ \\
\hline Mace & AGT & 2008 & grain & $\begin{array}{l}\text { Mace has broad adaptation, consistently high relative yield under a wide range of conditions and is less } \\
\text { susceptible to downgrading at receival due to black point, pre-harvest sprouting, or screenings losses } \\
\text { than many other cultivars. An awned variety of medium height. }\end{array}$ \\
\hline Scout & LongReach $^{5}$ & 2009 & grain & $\begin{array}{l}\text { Mid-season maturity. Medium to long coleoptile with good early vigour. Performs well in both alkaline } \\
\text { and acid soils. Contains the Commonwealth Scientific and Industrial Research Organisation (CSIRO, } \\
\text { Australia) Transpiration Efficiency gene, which confers improved water use efficiency. }\end{array}$ \\
\hline Suntop & AGT & 2012 & grain & $\begin{array}{l}\text { A main season line with stable yields in areas with both low to high yield potential. More rapidly } \\
\text { maturing than Gregory but similar in maturity to Janz CL with outstanding disease resistance and } \\
\text { wide adaptation. }\end{array}$ \\
\hline Trojan & LongReach & 2013 & grain & $\begin{array}{l}\text { Mid-long season maturity suited to the medium-high rain zone. Short-medium plant height at maturity } \\
\text { with good straw strength. }\end{array}$ \\
\hline Wedgetail & EGA & 2002 & dual purpose & $\begin{array}{l}\text { Dominant winter wheat. Tolerant of acid soils, early sowing cultivar. Large grain size. Adapted to } \\
\text { higher rainfall regions of the wheat belt. }\end{array}$ \\
\hline Whistler & & 1998 & dual purpose & $\begin{array}{l}\text { Early maturing and the quickest of the winter wheats. Relatively low 'cold requirement' and heads } \\
\text { prematurely when sown early as a dual-purpose crop. }\end{array}$ \\
\hline
\end{tabular}

\footnotetext{
Australian Grain Technologies, ${ }^{2}$ bred by William Farrer in $1901,{ }^{3}$ Cereal rye was used as a control in all the field trials, ${ }^{4}$ Enterprise Grains Australia, ${ }^{5}$ LongReach Plant Breeders.
} 


\section{Results}

\subsection{Local Rainfall and Dominant Weeds}

Monthly rainfall received during the growing season is reported in Table 2 for both locations from 2014 to 2016. Given the variable rainfall conditions across years, wheat cultivars also exhibited variable performance under the average (2015) and above average (2016) rainfall conditions experienced. Due to the above-average in-crop rainfall in 2016, significantly greater weed pressure was observed based on weed count biomass assessments at both locations. At Condobolin and Wagga Wagga, weed counts and biomass increased by $84.8 \%$ and $82.3 \%$ and $94.8 \%$ and $97.0 \%$, respectively in 2016 compared to 2015 .

The dominant weed observed in Condobolin plots was stonecrop (Crassula spp. L.), which was similar to the previous findings of Lemerle et al. (1996). Other common weeds at Condobolin included annual ryegrass (Lolium rigidum Gaud.) capeweed (Arctotheca calendula (L.) Levyns) and bluebell (Hyacinthoides non-scripta (L.) Chouard ex Rothm.). At the Wagga Wagga site, in-crop weeds included fumitory (Fumaria spp. L.), bluebell, capeweed, poppy (Papaver spp. L.), annual ryegrass, and barley grass (Hordeum murinum L.), all of which are commonly encountered in the mixed cropping zone of the Riverina region in south-eastern Australia [36]. Other weeds present at lower densities in Wagga Wagga included stonecrop and fleabane (Conzya bonariensis (L.) Cronq.).

To measure weed seed abundance and the type of weeds in the seedbank, we counted the germinated seedlings. Table 3 presents the densities of weed species germinations of the soil cores from both trial sites collected each year at sowing. The most prevalent weeds at Wagga Wagga were windmill grass (Chloris truncata R.Br.), bluebell, and fumitory, as well as Hillman's panic grass (Panicum hillmanii L.), fat hen (Chenopodium album L.), and sow thistle (Sonchus oleraceus L.). At Condobolin, stonecrop and witchgrass (Panicum capillare L.) were the most prevalent in the weed seedbank samples, and others observed included shepherd's purse (Capsella bursa-pastoris (L.) Medik.), fat hen, and windmill grass. 
Table 2. Monthly rainfall (mm) and the total in-crop rainfall for the Wagga Wagga and Condobolin canola field trial sites in 2014, 2015, and 2016 from Australian government bureau of meteorology.

\begin{tabular}{|c|c|c|c|c|c|c|c|c|c|c|c|c|c|c|c|}
\hline Wagga Wagga & Jan & Feb & Mar & Apr & May & Jun & Jul & Aug & Sep & Oct & Nov & Dec & Total & STDV & In-crop $x$ \\
\hline 2014 & 13.2 & 27.2 & 63.4 & 56.6 & 47.0 & 81.0 & 24.2 & 10.6 & 36.6 & 22.0 & 47.0 & 29.0 & 457.8 & 21.35 & 325.0 \\
\hline 2015 & 89.0 & 41.2 & 2.0 & 56.4 & 18.8 & 66.0 & 60.0 & 98.8 & 22.7 & 10.0 & 92.2 & 30.2 & 587.3 & 33.25 & 424.9 \\
\hline 2016 & 58.6 & 20.0 & 42.6 & 10.8 & 102.1 & 99.7 & 86.8 & 68.1 & 178.0 & 79.1 & 28.0 & 53.5 & 827.3 & 45.58 & 652.6 \\
\hline Condobolin & Jan & Feb & Mar & Apr & May & Jun & Jul & Aug & Sep & Oct & Nov & Dec & Total & STDV & In-crop \\
\hline 2014 & 35.2 & 46.7 & 104.5 & 28.0 & 27.6 & 57.4 & 9.2 & 22.2 & 11.0 & 11.5 & 17.7 & 88.6 & 459.6 & 31.00 & 184.6 \\
\hline 2015 & 59.2 & 35.9 & 0.2 & 64.7 & 11.6 & 31.8 & 41.2 & 42.3 & 6.8 & 65.2 & 67.3 & 28.5 & 454.7 & 23.40 & 330.9 \\
\hline Long-term average * & 42.6 & 36.9 & 37.4 & 33.4 & 34.7 & 37.5 & 33.6 & 35.2 & 31.7 & 39.5 & 35.4 & 39.5 & 437.4 & 3.08 & 288.4 \\
\hline
\end{tabular}

sowing and crop maturity. 
Table 3. The total glasshouse seedbank weed species germination density (seedlings $/ \mathrm{m}^{2}$ ) generated in the topsoil from Condobolin and Wagga Wagga trial sites taken at crop sowing in 2015 and 16 (based on four counts).

\begin{tabular}{|c|c|c|c|c|c|c|}
\hline \multirow{2}{*}{$\begin{array}{c}\text { Wagga Wagga } \\
\text { Replicate }\end{array}$} & \multicolumn{6}{|c|}{ Weed count } \\
\hline & Fumaria spp L. & $\begin{array}{c}\text { Chloris truncata } \\
\text { R.Br. }\end{array}$ & $\begin{array}{c}\text { Hyacinthoides } \\
\text { non-scripta L. }\end{array}$ & $\begin{array}{l}\text { Chenopodium } \\
\text { album } \mathrm{L} .\end{array}$ & Sonchus oleraceus L. & Panicum spp. L. \\
\hline 1 & 16 & 6 & 15 & 0 & 0 & 2 \\
\hline 2 & 3 & 26 & 28 & 0 & 0 & 5 \\
\hline 3 & 4 & 6 & 3 & 1 & 1 & 1 \\
\hline 4 & 16 & 17 & 26 & 1 & 0 & 1 \\
\hline 5 & 39 & 15 & 16 & 1 & 0 & 2 \\
\hline 6 & 2 & 25 & 2 & 0 & 1 & 1 \\
\hline Total & 80 & 95 & 90 & 3 & 2 & 12 \\
\hline \multicolumn{7}{|l|}{ Condobolin } \\
\hline Replicate & Crassula spp. L. & $\begin{array}{c}\text { Chloris truncata } \\
\text { R.Br. }\end{array}$ & $\begin{array}{l}\text { Hyacinthoides } \\
\text { non-scripta L. }\end{array}$ & $\begin{array}{l}\text { Chenopodium } \\
\text { album L. }\end{array}$ & $\begin{array}{l}\text { Capsella bursa-pastoris } \\
\text { (L.) Medik. }\end{array}$ & Panicum spp. L. \\
\hline 1 & 9 & 1 & 0 & 1 & 0 & 1 \\
\hline 2 & 8 & 0 & 0 & 0 & 0 & 3 \\
\hline 3 & 4 & 0 & 0 & 0 & 0 & 2 \\
\hline 4 & 29 & 0 & 0 & 1 & 0 & 3 \\
\hline 5 & 16 & 0 & 0 & 0 & 2 & 0 \\
\hline 6 & 1 & 2 & 0 & 0 & 0 & 2 \\
\hline Total & 67 & 3 & 0 & 2 & 2 & 11 \\
\hline
\end{tabular}




\subsection{Early Crop Biomass Differences and Weed Biomass Interference}

Wheat cultivar often impacted both crop and weed biomass accumulation as well as weed count in both years $(p<0.001)$ and locations $(p<0.001)$ (Table 4$)$. Cultivar differences in early crop biomass accumulation were significant at the elongation growth stage at both locations and years, but no differences were observed at the booting/flowering growth stage at either location in 2016. The cultivars that consistently harboured fewer weeds in both years and locations included Federation, Condo, and Janz CL, while Gregory in 2015 and Mace in 2016 (Figures 1 and 2) were less weed competitive. Certain cultivars exhibited reduced weed establishment in one year and location, but not both (e.g., Scout and Trojan at Condobolin and Mace and Wedgetail at Wagga Wagga in 2015).

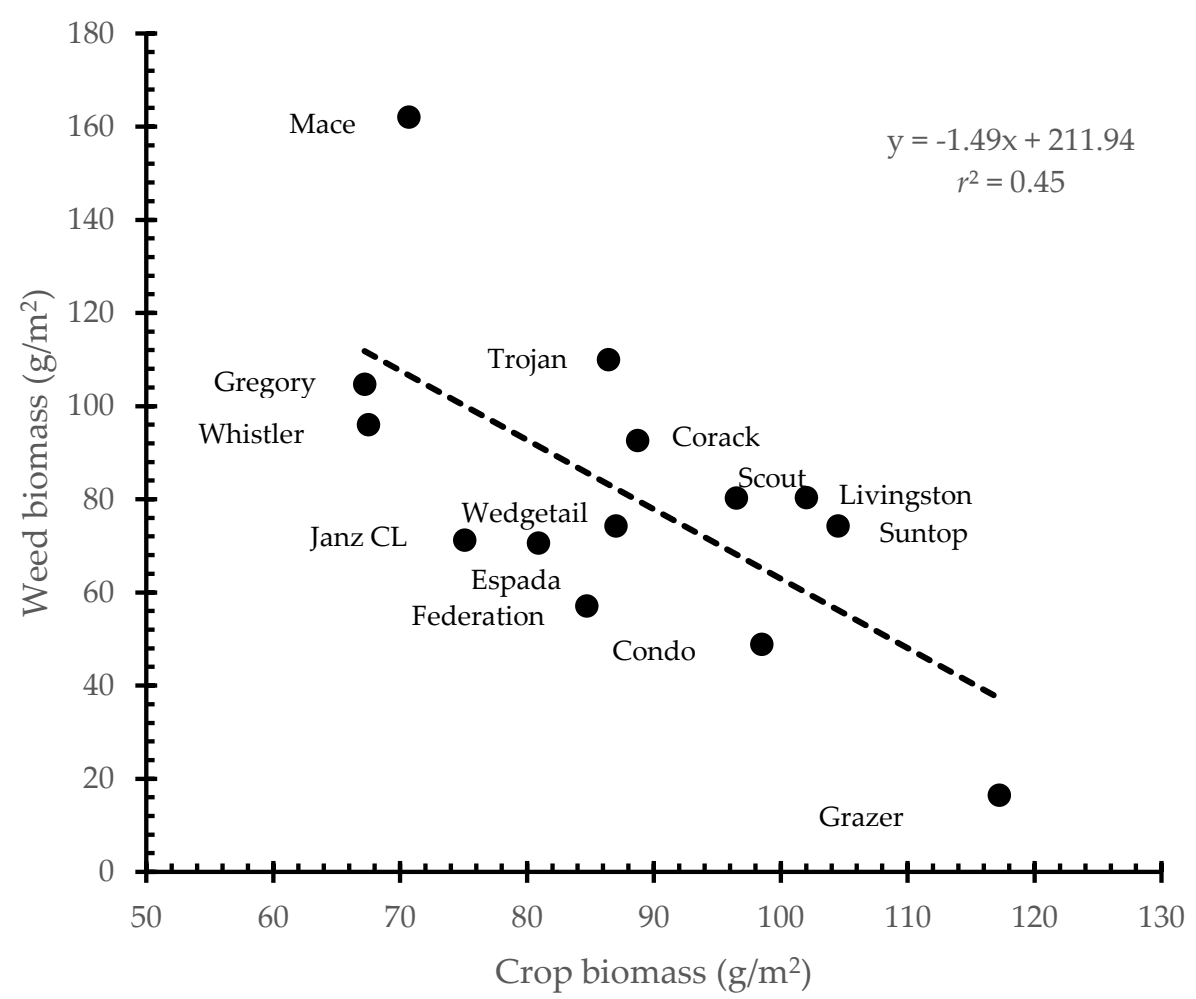

Figure 1. The relationship between mean wheat cultivar early biomass and weed biomass at crop maturity before flowering at Condobolin in 2015 and 2016. Each data value represents the average of the two-year mean of six replicates for each year.

At 100 days after seeding, cultivar Condo was $82.8 \%$ and $97.1 \%$ more weed-competitive than the older industry-standard cultivar Gregory in 2015 at Condobolin and Wagga Wagga, respectively (Table 4). However, as higher in-crop rainfall (Table 2) resulted in higher weed pressure in 2016 at both locations, Condo was only $47.4 \%$ and $28.1 \%$ more weed-competitive than Gregory at Condobolin and Wagga Wagga, respectively (Table 4). However, Mace harboured more weeds in crop at both locations in 2016. Federation, a heritage cultivar with early vigour and upright growth habit, was typically the most weed-competitive cultivar in both locations and years in this experiment and also experimentation conducted previously at both sites. 


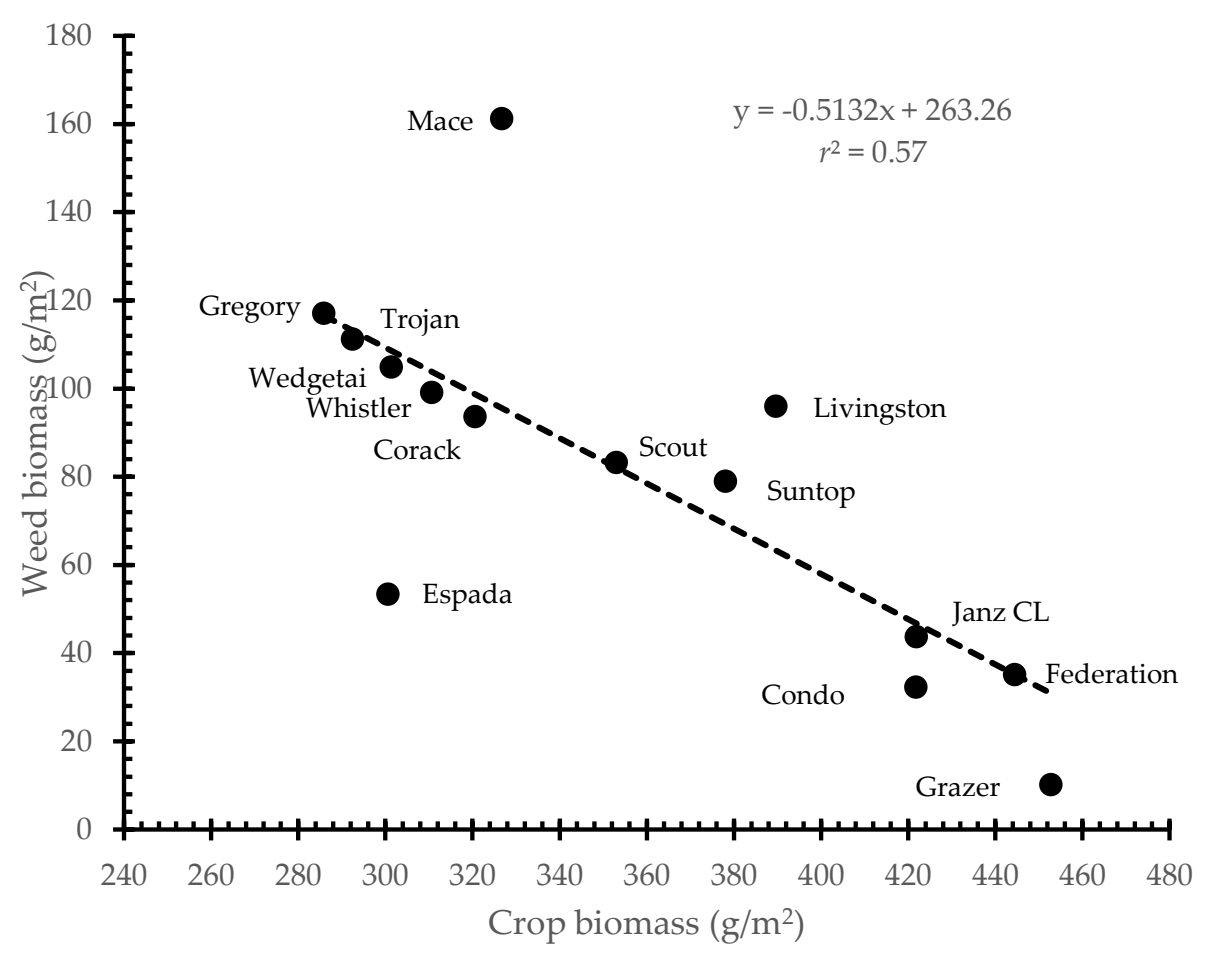

Figure 2. The relationship between mean wheat cultivar early biomass and weed biomass at crop maturity before flowering at Wagga Wagga in 2015 and 2016. Each data value represents the average of the 2-year mean of six replicates for each year.

Weed count and biomass differed depending on the location $(p<0.001)$ with significant cultivar, year, and location interactions. The accumulation of crop biomass early in the season also resulted in reduced weed biomass at both locations, which was a relationship that was negatively correlated (coefficient of determination $\left(r^{2}\right)$ of $0.45(p<0.001$, Figure 1$)$ at both Condobolin and $0.57(p<0.001$, Figure 2) at Wagga Wagga (Table 4).

\subsection{Weed Suppression by Other Crop Canopy Traits}

Cultivar differences were observed for all parameters associated with crop growth and vigour including early vigour, PAR light interception (\%), leaf area index, normalised difference vegetation index (NDVI), and plant height $(p<0.001)$, with significant cultivar, year, and location interactions $(p<0.001)$. The ranking of cultivars based on these individual parameters indicated that cultivars with highest early growth vigour, light interception as measured by LAI and PAR, leaf area, and plant height were also the most weed suppressive (Tables S1 and S2).

At the early crop growth stage, PAR light interception and LAI were positively correlated with weed suppression across the years and locations $(p<0.001)$. At Wagga Wagga, the coefficient of determination was $r^{2}=0.97$ and 0.94 in 2015 and 2016, respectively, while at Condobolin, $r^{2}$ was 0.89 and 0.22 , respectively. The cultivars with the highest PAR light interception also exhibited higher leaf area indices as well as lower weed biomass (e.g., Federation and Condo, Table 4, Tables S1 and S2).

\subsection{Modelling for Weed Suppression Using Crop Canopy Traits}

PLS regression predictive linear model results for weed suppression by commercial wheat cultivars are presented in Figure 3 by location and year based on weed dry biomass as the response variable and selected above-ground crop canopy traits (crop biomass, PAR light interception, leaf area index, visual vigour ratings, plant height, and NDVI) as the predictive variables. 
Table 4. Wheat cultivar differences in average crop biomass $\left(\mathrm{g} / \mathrm{m}^{2}\right)$ at crop elongation and booting growth stages, in-crop weed count (plants/ $\left.\mathrm{m}^{2}\right)$, and weed dry biomass $\left(\mathrm{g} / \mathrm{m}^{2}\right)$ at crop maturity (including weed suppression percentage in the brackets expressed in comparison to the less suppressive cultivar in the same year and location) at Condobolin and Wagga in 2015 and 2016. Each data value is a mean of six replicates.

\begin{tabular}{|c|c|c|c|c|c|c|c|c|c|c|c|c|c|c|c|c|}
\hline \multirow{3}{*}{$\begin{array}{c}\text { Item } \\
\text { Site } \\
\text { Cultivar/year }\end{array}$} & \multicolumn{4}{|c|}{ Elongation Dry Biomass } & \multicolumn{4}{|c|}{ Booting Dry Biomass } & \multicolumn{4}{|c|}{ Maturity Weed Count } & \multicolumn{4}{|c|}{ Maturity Dry Weed Biomass } \\
\hline & \multicolumn{2}{|c|}{ Condo } & \multicolumn{2}{|c|}{ Wagga } & \multicolumn{2}{|c|}{ Condo } & \multicolumn{2}{|c|}{ Wagga } & \multicolumn{2}{|c|}{ Condo } & \multicolumn{2}{|c|}{ Wagga } & \multicolumn{2}{|c|}{ Condo } & \multicolumn{2}{|c|}{ Wagga } \\
\hline & 2015 & 2016 & 2015 & 2016 & 2015 & 2016 & 2015 & 2016 & 2015 & 2016 & 2015 & 2016 & 2015 & 2016 & 2015 & 2016 \\
\hline Condo & 44.7 & 152.3 & 720.7 & 122.7 & 433 & 1063 & 870 & 1066.5 & 204 & 5058 & 27 & 575 & $7.6(82.8)$ & $90.2(71.3)$ & $\begin{array}{c}0.14 \\
(97.1)\end{array}$ & 64.5 (79.9) \\
\hline Corack & 45.5 & 131.9 & 531.4 & 109.7 & 443 & 798.1 & 782 & 971.8 & 375 & 3936 & 33 & 1126 & $25.4(42.7)$ & $159.7(49.2)$ & $2.6(47.8)$ & $185.6(42.2)$ \\
\hline Espada & 42.8 & 119 & 486.8 & 114.2 & 378 & 908.1 & 770 & 992.4 & 262 & 4326 & 14 & 480 & $11.9(73.1)$ & $129.2(58.9)$ & $0.6(87.8)$ & $106.2(66.9)$ \\
\hline Federation & 63.7 & 105.7 & 765.1 & 123.7 & 433 & 887.2 & 738 & 1007.9 & 297 & 4195 & 5 & 705 & $12.4(72.0)$ & $101.7(67.6)$ & $0.0(100)$ & $70.1(78.2)$ \\
\hline Grazer-rye & 78.4 & 156 & 737.1 & 168.3 & 530 & 939.3 & 1041 & 986.8 & 298 & 4603 & 3 & 226 & $5.5(87.6)$ & $27.5(91.2)$ & $0.0(100)$ & $20.3(93.7)$ \\
\hline Gregory & 43.8 & 90.6 & 464.5 & 107.1 & 299 & 928.1 & 671 & 812.8 & 347 & 4331 & 19 & 904 & $44.3(0.0)$ & $165.2(47.4)$ & $4.9(0.0)$ & $231.0(28.1)$ \\
\hline Janz CL & 47.2 & 103 & 707.9 & 135.7 & 349 & 714.3 & 742 & 972.8 & 245 & 3522 & 11 & 536 & $21.1(52.4)$ & $121.2(61.4)$ & $0.3(93.7)$ & $87.0(72.9)$ \\
\hline Livingstone & 57.3 & 146.6 & 672.3 & 106.9 & 430 & 941 & 759 & 972.4 & 483 & 4545 & 24 & 915 & $11.6(73.8)$ & $149.3(52.5)$ & $3.8(22.0)$ & $188.9(41.2)$ \\
\hline Mace & 46.4 & 95 & 539.6 & 113.7 & 412 & 861.1 & 924 & 893 & 455 & 4091 & 17 & 442 & $10.2(77.0)$ & $314.1(0.0)$ & $1.2(75.9)$ & $321.2(0.0)$ \\
\hline Scout & 38.9 & 154 & 587.7 & 118.3 & 415 & 1022.1 & 770 & 978.7 & 464 & 4903 & 43 & 927 & $1.8(95.9)$ & $158.8(49.4)$ & $2.2(55.9)$ & $164.9(48.7)$ \\
\hline Suntop & 51.6 & 157.3 & 639.6 & 116.4 & 418 & 1082 & 777 & 969.6 & 435 & 5155 & 23 & 974 & $16.3(63.2)$ & $132.4(57.8)$ & $2.6(46.1)$ & $157.0(51.1)$ \\
\hline Trojan & 46.3 & 126.5 & 489.4 & 95.5 & 379 & 1005.9 & 696 & 922.7 & 391 & 4754 & 16 & 1079 & $4.9(88.9)$ & $215.1(31.5)$ & $4.3(13.3)$ & $221.3(31.1)$ \\
\hline Wedgetail & 42.6 & 131.4 & 479.1 & 123.6 & 244 & 1059.3 & 647 & 733.7 & 442 & 4997 & 21 & 523 & $9.4(78.8)$ & $139.2(55.7)$ & $0.2(96.9$ & $209.7(34.7)$ \\
\hline Whistler & 39.3 & 95.7 & 531.4 & 89.8 & 305 & 1122.5 & 645 & 838.9 & 497 & 5105 & 16 & 857 & $18.5(58.2)$ & $173.6(44.7)$ & $2.4(52.0)$ & $197.3(38.6)$ \\
\hline Mean & 49.2 & 126.1 & 596.6 & 117.5 & 390.6 & 952.3 & 773.7 & 937.1 & 371.1 & 4537.2 & 19.4 & 733.5 & 14.4 & 148.4 & 1.8 & 158.9 \\
\hline LSD & 17.8 & 35.6 & 188.8 & 38.5 & 119.1 & 362.4 & 130.2 & 208 & 121.8 & 1559.4 & 15.3 & 320.4 & 10.7 & 15.1 & 1.4 & 135.5 \\
\hline$p$ value ${ }^{\mathrm{a}}$ & $* * *$ & $*$ & $* *$ & * & $* * *$ & ns & $* * *$ & ns & $* *$ & ns & $*$ & $* * *$ & $* *$ & $* * *$ & $* *$ & $* *$ \\
\hline
\end{tabular}

a $p$ value: $* * *=p<0.001, * *=p<0.01^{*}=p<0.05, \mathrm{~ns}=$ not significant, Least significant difference (LSD), cultivar weed suppression effectiveness is shown in the brackets in comparison

with the least suppressive cultivar. The bold numbers indicate the least weed competitive cultivar in that year and location. 
VIPs ( 1 Comp / $95 \%$ conf. interval)

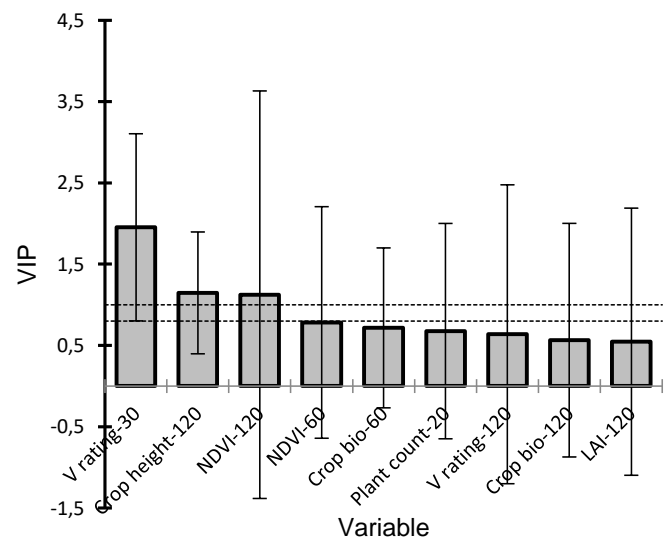

(a)

VIPs (1 Comp / 95\% conf. interval)

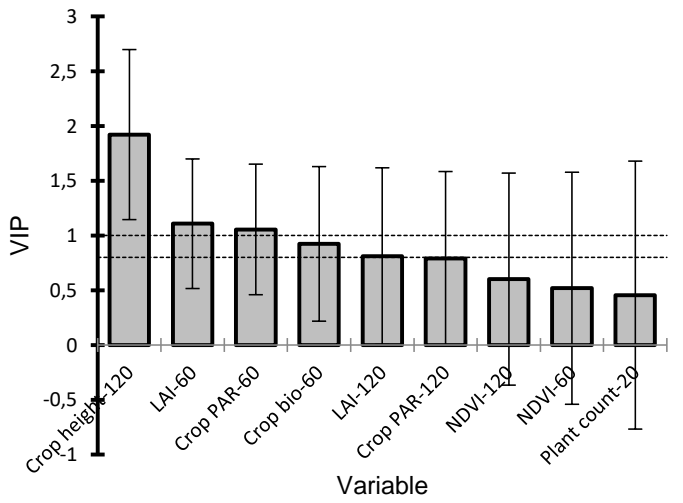

(c)
VIPs (1 Comp / 95\% conf. interval)

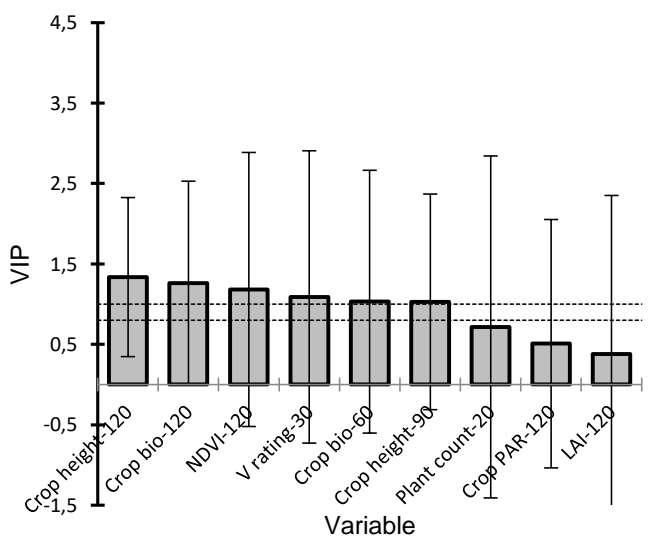

(b)

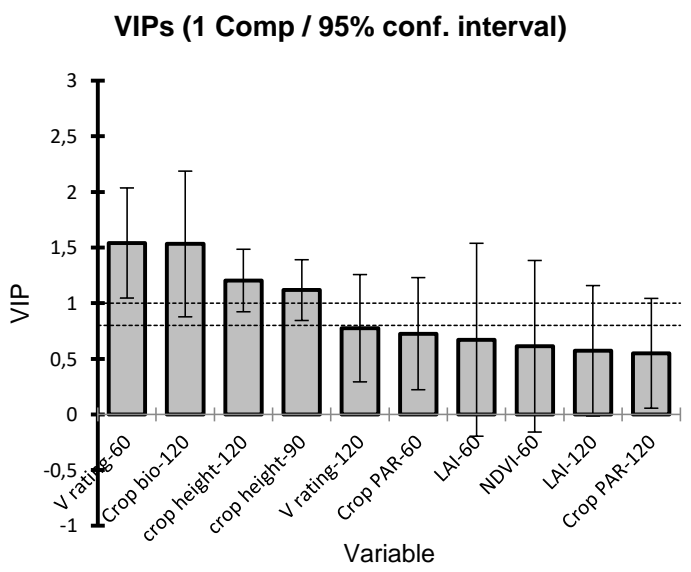

(d)

Figure 3. Condobolin 2015-120 days after crop emergence (DAE) regression model $r^{2}=0.21$ (a). Wagga Wagga 2015-120 DAE regression model $r^{2}=0.29$ (b). Condobolin 2016-120 DAE regression model $r^{2}=0.51$ (c). Wagga Wagga 2016-120 DAE regression model $r^{2}=0.62(\mathrm{~d})$. Commercial wheat partial least squares regression (PLS-R) based on weed dry biomass as the response variable at 120 DAE showing the variable importance in model projection (VIP) values by several independent crop canopy traits (taken at various DAE) in 2015 and 2016 at Condobolin $(\mathbf{a}, \mathbf{c})$ and Wagga Wagga (b,d). The dotted border line in the graphs identifies the VIPs that are greater than 0.8 and above: these variable thresholds are either moderately $(0.8<$ VIP $<1)$ or highly influential (VIP $>1)$ in weed suppression. The canopy traits include crop biomass, PAR percentage of light interception, leaf area index, visual vigour ratings, plant height, and normalised difference vegetative index (NDVI).

In 2015, the model prediction variables differed in accordance with crop growth stage and impact in interfering with weed biomass at both locations (Condobolin $r^{2}=0.21$, Figure 3a; Wagga Wagga $r^{2}=0.29$, Figure $3 b$ ). For the Condobolin crop, early visual vigour, crop height, and NDVI at vegetative VIPs were highly influential (VIP > 1), while crop biomass (at early and vegetative), early NDVI, and plant count VIP scores were moderate. At Wagga Wagga, the VIP scores of crop height (at early and vegetative), crop biomass (early and vegetative), NDVI (vegetative), and visual vigour rating suggested that these variables were highly influential in weed suppression in-crop. In both locations, PAR light interception and LAI VIP value thresholds were moderate in weed suppression $(0.8<$ VIP $<1)$. 
In 2016, a year with above average rainfall, the model predictions showed a significant inverse correlation $(p<0.001)$ of most predictors with weed biomass $\left(r^{2}=0.51\right.$ at Condobolin, $r^{2}=0.62$ at Wagga Wagga). At Condobolin, in contrast to 2015, strong influential predictor variable VIPs (VIP $>0.8$ ) included crop height (early, vegetative), LAI (early, vegetative) and early crop biomass and PAR (early) (Figure 3c). At Wagga Wagga, vigour rating (early), crop biomass (vegetative), and height (early, vegetative) had influential VIPs, while PAR (early, vegetative), LAI (early, vegetative), and early NDVI had moderate projection importance $(0.8<$ VIP $<1)$ (Figure 3d).

Overall, the PLS regression model analysis in 2015 demonstrated that weed biomass was generally inversely related to early crop vigour rating, vegetative NDVI, and height at both locations. In addition, at Wagga Wagga, early and vegetative crop biomass was highly influential. By contrast in 2016, early crop vigour, biomass, and height had the highest and stronger projection importance at both locations. However, at Condobolin, LAI and PAR light interception were also highly influential in weed suppression. Not surprisingly, the projection importance of all the canopy traits assessed varied with crop growth stage, location and year.

\subsection{Cultivar Grain Yield versus Weed Suppression}

In 2015 and 2016, grain yield differed significantly between cultivars and locations (Table 5). At Wagga Wagga, there were differences in yield between cultivars and years (2015 higher than 2016), while interestingly, at Condobolin, cultivar differences were only noted between years, with higher yields in 2016 than in 2015 for all cultivars. It should be noted that in 2016 moisture was not limiting in both locations. The heritage cultivar Federation, developed in central NSW in the late 1800s, was consistently the most weed suppressive over year and location, but its yield potential was $10 \%$ to $55 \%$ less than recently improved cultivars (Table 5). Condo, Espada, and Janz CL consistently produced higher yields while suppressing weeds moderately to exceptionally well.

Table 5. Mean wheat cultivar grain yield ( $\mathrm{t} / \mathrm{ha})$ and weed biomass $\left(\mathrm{g} / \mathrm{m}^{2}\right)$ at crop maturity at Condobolin and Wagga Wagga in 2015 and 2016.

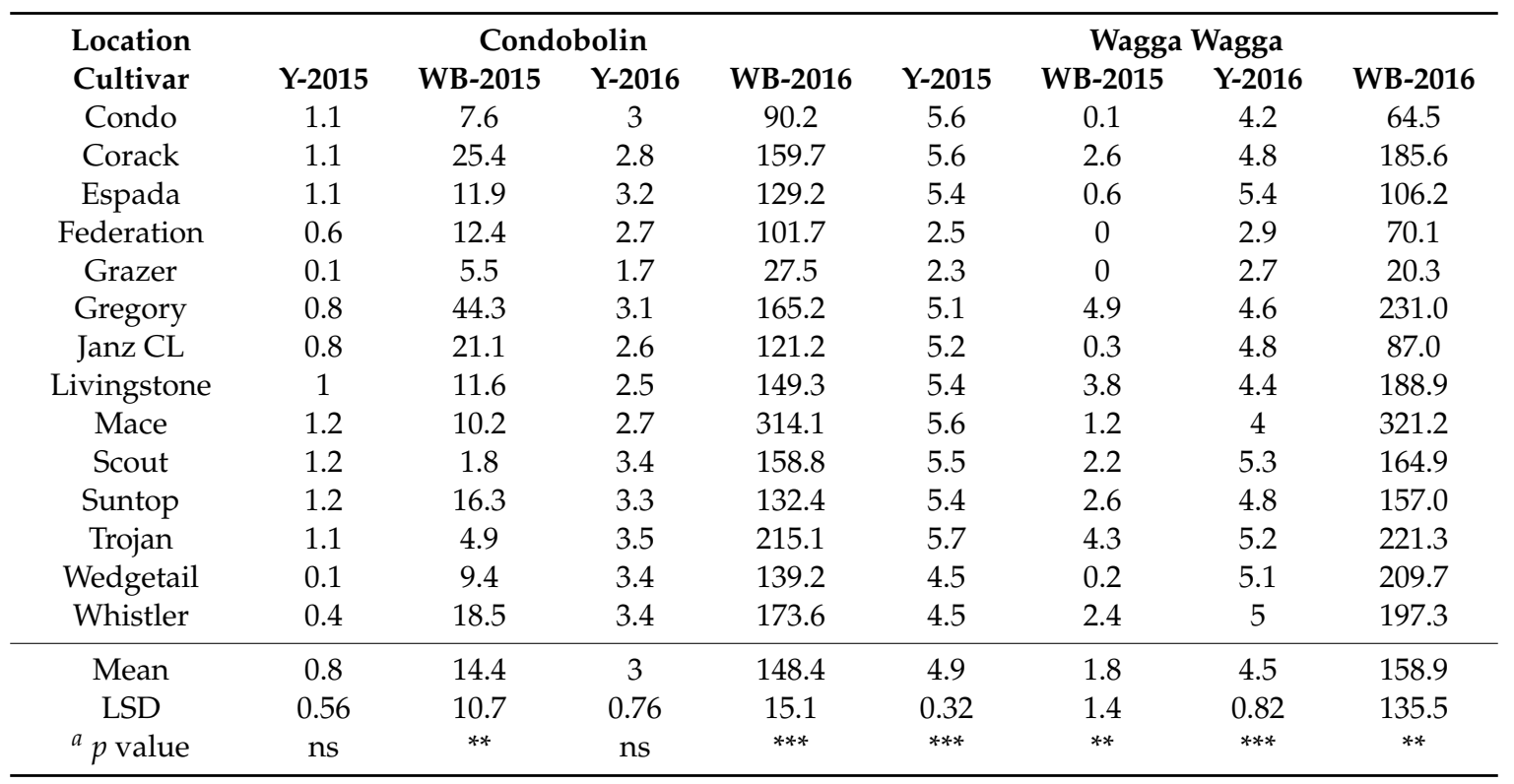

${ }^{\text {a }} p$ value: ${ }^{* * *}=p<0.001,{ }^{* *}=p<0.01, \mathrm{~ns}=$ not significant, $\mathrm{Y}=$ grain yield, $\mathrm{WB}=$ weed biomass. Least significant difference (LSD).

There were significant differences in both years between cultivars in yield at Wagga Wagga $(p<0.001)$ but not at Condobolin. In 2015, at Condobolin, yield may have been negatively impacted by the sudden rise in daily maximum temperature to $35.2,36.0$, and $33.4{ }^{\circ} \mathrm{C}$ for three consecutive days at grain fill in October (Figure 4). In 2016, there were clear differences in weed biomass over cultivars, 
with a coefficient of determination was $r^{2}=0.58$, although yield did not differ between cultivars (Condobolin, Table 5). At Wagga Wagga in 2015, the coefficient of determination was $r^{2}=0.25$ (figure not presented, $p<0.001$ ), with four cultivars being more weed suppressive including Federation, Condo, Espada, and Janz CL. In 2016, the same cultivars were also the most weed suppressive $\left(r^{2}=0.45\right.$; $p<0.001$ ), with cultivar differences in yield and dry weed biomass (Table 5).

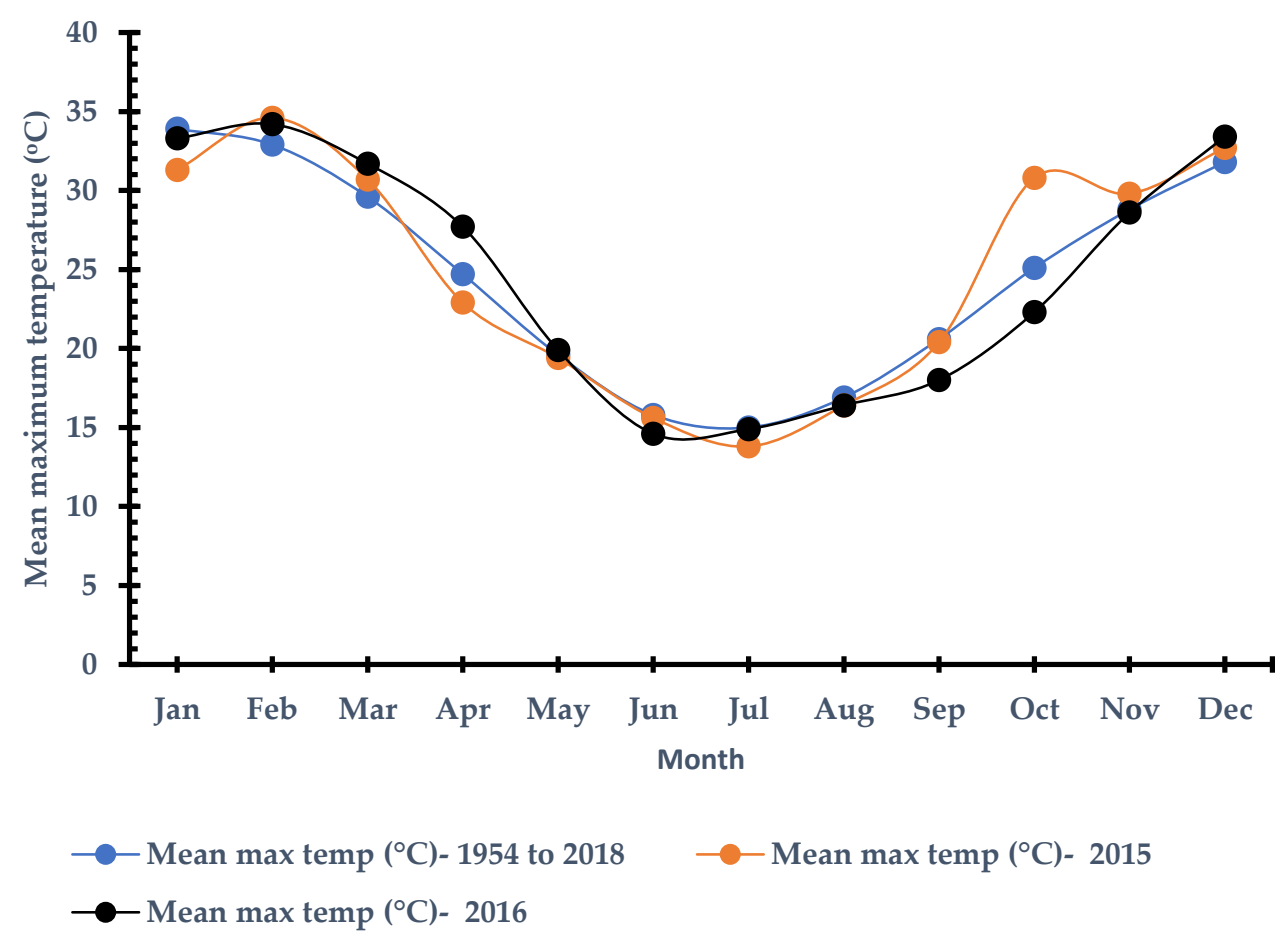

Figure 4. Condobolin mean maximum temperature for 2015 to 2016 (050052 Condobolin Agricultural Research Station, Australian Bureau of Meteorology).

\section{Discussion}

Previous studies addressing the factors influencing cereal crop competitiveness against weeds have attempted to assess competitiveness by evaluating total weed numbers and biomass, in relation to crop growth and yield produced, with an emphasis on crop traits easily assessed above ground $[20,22,25,34,37]$, including crop height and total biomass produced at maturity, or at various time points during crop maturity. In recent years, Australian wheat breeders have shown that early wheat vigour is particularly important in negatively impacting weed establishment and weed growth in crop $[17,38]$. In this study, we investigated a number of key crop parameters influencing early canopy formation such as leaf area, light interception, early vigour, and crop biomass, as well as impacts on weed establishment. In addition, we applied PLS modelling techniques to further estimate which crop parameters were the most influential in reducing weed numbers and weed biomass. This study was performed over multiple locations and years and addressed both genetic and environmental factors that impacted cultivar performance and weed establishment using both currently commercial and historic Australian winter wheat cultivars for comparative purposes. Historic cultivars were included, as they have been shown to be particularly suppressive to weeds in crop in past experimentation [39].

Early biomass accumulation in wheat cultivars in this study was strongly and negatively correlated with weed biomass over both locations and years, indicating potential heritable competitive ability against weeds. Biomass accumulation early in the season is impacted by early vigour in wheat. Early vigour has been shown previously to be related to crop establishment and the rate of canopy development, and it has been correlated with morphological leaf traits such as leaf area and leaf width in the earliest phases of wheat growth [17]. Korres and Froud-Williams [40] also reported that crop 
height and rapid tillering capacity in winter wheat cultivars were associated with improved weed suppression in experimentation with a diverse weed flora.

From the findings generated in this experiment and those of our collaborating plant breeders at CSIRO [17,38], the selection of traits supporting early crop vigour in wheat breeding programs as demonstrated by greater early leaf area accumulation and crop biomass can result in superior weed-competitive cultivars, leading to significantly reduced weed biomass and weed numbers, at similar planting densities to other commercial cultivars. Importantly, from a longer-term perspective, substantial genetic gain in yield may be achieved if breeders are able to select for cultivars exhibiting faster early growth rates and also greater biomass at maturity [41], because greater early vigour has the potential to also result in increased water- and nutrient-use efficiency, as well as enhanced weed competitiveness, thereby increasing crop yields and profitability [42].

In this study, we have demonstrated that significant cultivar differences existed with respect to early crop vigour, PAR light interception (\%), leaf area index, NDVI, and plant height. In addition, cultivar, year, and location interactions were frequently significant. However, PLS modelling clearly showed that only a few crop parameters-specifically early vigour, crop height, and total crop biomass-were strongly and negatively correlated with weed biomass accumulation. This is an important finding and may have relevance for future breeding efforts attempting to estimate crop competitiveness more accurately using various genotypes, in multiple locations. Interestingly, the cultivars consistently demonstrating the highest early growth vigour, light interception, leaf area, and plant height (Federation and Condo) were also the most weed suppressive across all locations and years analysed, demonstrating the importance of early crop vigour, leading to a closed canopy early in the season to result in effective weed suppression. Didon and Hansson [43] recently demonstrated that the most weed-suppressive barley cultivars were those that intercepted the most PAR. However, in the current study, PAR percentage of light interception and LAI VIP value thresholds were moderate in driving weed suppression $(0.8<$ VIP $<1)$ except at Condobolin (2016) when VIP values were influential (VIP > 1).

Our study findings also support the hypothesis that several key crop canopy traits contribute to superior cultivar weed competitive ability, and therefore single trait measurement is often not a strong indicator of competitive ability. For example, taller wheat cultivars have been reported to better tolerate weed pressure and reduce weed growth [16], similar to our findings with the heritage cultivar, Federation, which is typically very tall, but is also vigorous in forming an early closed canopy and is therefore weed suppressive. Recently, Wicks et al. [37] reported that several shorter wheat cultivars exhibited significant weed suppression in contrast to taller cultivars [37], suggesting that competitive ability is not necessarily associated with only a single trait [6].

Our findings and those of Australian cereal breeders have suggested that a combination of several crop canopy morphological traits contribute effectively to crop competitive ability, and these typically include height, light interception, leaf area, and inclination. In our study, height was not an exceptionally strong predictor of weed suppression for most cultivars, as today's wheat cultivars are all semi-dwarf and frequently exhibit similar height. However, Federation, the tallest cultivar in the trials, was exceptionally weed suppressive over both years and locations. Unfortunately, it also possesses a tendency to lodge, but this was not observed even in years with high moisture at either location.

In the current study, recent commercial cultivars (e.g., Trojan) produced high yields despite being less weed suppressive. This suggests that under certain environmental conditions, the competitive ability of the current commercial cultivars in weed tolerance may not always be linked with weed suppression, especially in drier years with less weed infestation. Mechanisms of weed tolerance may be independent of suppressive traits [44,45]. For example, Fradgley et al. [13] reported that taller varieties of oats (Avena sativa L.) tended to be more weed tolerant but not necessarily more suppressive. Further studies are required to differentiate crop interference and to determine the relationship between weed suppression and weed tolerance in wheat cultivars.

The wide use of semi-dwarf wheat genotypes has resulted in an increased harvest index in modern cultivars, with shorter plants and higher grain yield than older varieties [42] as demonstrated 
in this study. However, Richards et al. [38] reported that the shorter plant height is often associated with reduced early vigour, a pleiotropic and undesired effect of the high grain yield performance of modern semi-dwarf varieties. However, our findings and those of CSIRO breeders have demonstrated that some modern semi-dwarf wheat genotypes have high early growth vigour and also enhanced weed-suppression (e.g., Condo) [46]. This suggests that although the competitive ability of wheat has clearly been reduced by selection based on yield potential [7], there are some genotypes that could be used for weed management due to their weed-suppressive ability while maintaining yields. Our findings further suggest that canopy closure associated with early vigour is a major factor in their ability to suppress weeds.

Another key finding of this study was that the heritage cultivar Federation was one of the most weed-suppressive cultivars examined. Vandeleur and Gill [16] examined 14 historical wheat cultivars ranging in release date from 1860 to 1994 to determine the impact of crop breeding on the competitive ability to suppress weeds. Using oat as the weed, there was a significant positive linear relationship $\left(r^{2}=0.81, p<0.01\right)$ between the year of cultivar release and crop yield loss, suggesting an inferior competitive ability in modern cultivars compared to their ancestral counterparts. The older cultivars not only provided superior weed suppression but were also more tolerant of weeds as indicated by smaller yield loss. Similarly, older cultivars or landraces have been shown to be more competitive with weeds than the higher-yielding, semi-dwarf modern cultivars [7,26]. When sown at the same crop density, heritage crop stands had, on average, lower weed biomass (56\%) than modern crop stands [47], indicating superior weed suppression. These findings coupled with our study results suggest that re-examination of the value of some heritage wheat cultivars should be undertaken to provide additional options to the producer toolbox for wheat production in changing climatic conditions.

In 2015 and 2016, the PLS model indicated a clear inverse relationship between some of the cultivar traits related to canopy architecture/light interception and weed biomass at both locations. This relationship was stronger in 2016, with in-crop above average rainfall at both locations. This suggests that in a year when soil moisture is not limiting, the competitive advantage of the wheat crop is dramatically increased, suggesting that a lack of soil moisture could also be associated with reduced weed establishment and competitiveness in Australian dryland wheat production farming systems.

The PLS model showed that early crop growth vigour, crop biomass, NDVI, height, LAI, and PAR light interception (\%) all negatively impacted weed biomass, but the most negatively correlated predictors in both years and locations were narrowed down to crop vigour, crop biomass, and height. Our findings also show that the most competitive cultivars including Federation, Condo, and Janz CL had early canopy closure due to exceptional early growth vigour and biomass accumulation, resulting in early shading and the subsequent suppression of weeds.

In addition, seasonal changes may impact the crop weed-suppressive competitive ability as the model coefficient of determination was higher and more than double in 2016 at both locations (Condobolin: 21 versus 51, Wagga Wagga: 22 versus 59) when above-average rainfall was received. The model outcomes also suggest that early crop vigour is not a standalone trait but a combination of other cultivar traits including leaf area index, PAR light interception, and NDVI; clearly, early canopy closure positively impacts a cultivar's ability to suppress weed growth. A better understanding of the interaction between these plant traits and characteristics will assist breeders to develop weed-suppressive cereal crop cultivars in the future. Our current comparative studies with recently developed early vigour cultivars from CSIRO wheat breeders further suggests that early vigour (when defined as the ability of the crop to shade the soil by canopy architectural traits) before crop maturity (by 100 days after seeding) is positively correlated with weed suppression [46], and selection for such traits can result in enhanced weed suppression with respect to today's commercial cultivars. 


\section{Conclusions}

Our results clearly show that the establishment of competitive wheat cultivars can result in the effective suppression of weed growth (up to $90 \%$ or greater) in the absence of post-emergent herbicides. Significant differences between wheat cultivar and location and year were observed for crop biomass, early vigour, leaf area index, PAR light interception, crop height, weed number, weed biomass, and yield. However, PLS modelling applied in this study further suggested that the most influential factors in reducing weed numbers and establishment were early crop vigour, crop biomass accumulation, and height. Cultivar competitive traits were influenced by both genotype and environmental factors, as shown by clear differences in cultivar performance, yield, and weed suppression at each location and year. Cultivars Condo, Espada, and Janz were superior performers in terms of weed suppression and yielding potential in both locations and years, while the heritage cultivar Federation was the most weed-suppressive overall, but its yield potential was $10 \%$ to $55 \%$ less than recently improved cultivars.

Overall, our study results suggest that weed suppression is strongly associated with crop competitive ability early in the season, before boot stage and flowering. Clearly, in a year with adequate rainfall, the choice of wheat cultivar for yield potential and weed suppression impacts the subsequent ability of the crop to successfully interfere with weed growth. Therefore, when applying IWM strategies for weed management, the choice of cultivar is a potential tool for maintaining suitable grain yield in the presence of weeds and may reduce the need for subsequent herbicide application while potentially delaying the development of herbicide-resistant weeds. We look forward to the adoption of weed-suppressive traits by plant breeders when selecting future commercial cultivars for improved adaptation to dryland conditions.

Supplementary Materials: The following are available online at http://www.mdpi.com/2073-4395/10/7/983/s1. Table S1: Wheat cultivar differences in visual vigour ratings, PAR light interception (\%), leaf area index (LAI), normalised difference vegetation index (NDVI) and plant height $(\mathrm{cm})$ taken at the vegetative and flowering stage of the crop respectively, at Condobolin and Wagga Wagga in 2015. Table S2: Wheat cultivar differences in visual vigour ratings, PAR light interception (\%), leaf area index (LAI), normalised difference vegetation index (NDVI) and plant height $(\mathrm{cm})$ taken at the vegetative and flowering stage of the crop respectively, at Condobolin and Wagga Wagga in 2016.

Author Contributions: Conceptualization, J.M.M., W.B.B., and L.A.W.; methodology, investigation, J.M.M.; writing-original draft preparation, J.M.M., W.B.B. and P.A.W.; data curation, J.M.M. and P.A.W.; formal analysis, software, validation, J.M.M., P.A.W., L.A.W., H.W., J.D.W., and J.C.Q.; writing-review and editing, W.B.B. and L.A.W.; project administration and supervision, L.A.W.; resources, L.A.W.; funding acquisition All authors have read and agreed to the published version of the manuscript.

Funding: This research was funded by Grains Research and Development Corporation (GRDC) of Australia through project UCS 00020, 00022, and 00023 which provided project funding and post-graduate scholarship support for James Mwendwa.

Acknowledgments: We thank Richard McCullum (NSW DPI Condobolin ARAS), M. B Bagherieh-Najjar (Department of Biology, Golestan University, Iran), Graeme Heath and the Plant Interaction Research Group at Charles Sturt University for their assistance with field experimentation and data collection.

Conflicts of Interest: The authors declare no conflict of interest.

\section{References}

1. $\mathrm{Wu}, \mathrm{H}$. Integrating belowground non-chemical approaches for future weed management. In Weed and Pest Control: Molecular Biology, Practices and Environmental Impact; Travlos, I.S., Bilalis, D., Chachalis, D., Eds.; Nova Science Publishers Inc.: Hauppauge, NY, USA, 2016.

2. Jabran, K.; Mahajan, G.; Sardana, V.; Chauhan, B.S. Allelopathy for weed control in agricultural systems. Crop Prot. 2015, 72, 57-65. [CrossRef]

3. Heap, I. International Herbicide-Resistant Weed Database. Available online: www.weedscience.com (accessed on 30 September 2018).

4. Bajwa, A.A.; Walsh, M.; Chauhan, B.S. Weed management using crop competition in Australia. Crop. Prot. 2016, 30, 1-6. [CrossRef] 
5. Llewellyn, R.; Ronning, D.; Ouzman, J.; Walker, S.; Mayfield, A.; Clarke, M. Impact of Weeds on Australian Grain Production: The Cost of Weeds to Australian Grain Growers and the Adoption of Weed Management and Tillage Practices; Grains Research and Development Corporation and CSIRO: Canberra, Australia, 2016.

6. Andrew, I.K.S.; Storkey, J.; Sparkes, D.L. A review of the potential for competitive cereal cultivars as a tool in integrated weed management. Weed Res. 2015, 55, 239-248. [CrossRef] [PubMed]

7. Bertholdsson, N.-O.; Andersson, S.C.; Merker, A. Allelopathic potential of Triticum spp., Secale spp. And Triticosecale and use of chromosome substitutions and translocations to improve weed suppression ability in winter wheat. Plant Breed 2012, 131, 75-80. [CrossRef]

8. Worthington, M. Reberg-Horton, C. Breeding cereal crops for enhanced weed suppression: Optimizing allelopathy and competitive ability. J. Chem. Ecol. 2013, 39, 213-231. [CrossRef]

9. Travlos, I.S. Reduced herbicide rates for an effective weed control in competitive wheat cultivars. Intern. J. Plant Prod. 2012, 6, 1-14.

10. Milan, M.; Fogliatto, S.; Blandino, M.; Vidotto, F. Are Wheat Hybrids More Affected by Weed Competition than Conventional Cultivars? Agronomy 2020, 10, 526. [CrossRef]

11. Lazzaro, M.; Costanzo, A.; Bàrberi, P. Single vs multiple agroecosystem services provided by common wheat cultivar mixtures: Weed suppression, grain yield and quality. Field Crop. Res. 2018, 221, 277-297. [CrossRef]

12. Llewellyn, R.S.; Lindner, R.K.; Pannell, D.J.; Powles, S.B. Herbicide resistance and the adoption of integrated weed management by Western Australian grain growers. Agri. Econ. 2007, 36, 123-130. [CrossRef]

13. Fradgley, N.S.; Creissen, H.E.; Pearce, H.; Howlett, S.A.; Pearce, B.D.; Döring, T.F.; Girling, R.D. Weed suppression and tolerance in winter oats. Weed Tech. 2017, 31, 740-751. [CrossRef]

14. Bertholdsson, N.-O. Breeding spring wheat for improved allelopathic potential. Weed Res. 2010, 50, 49-57. [CrossRef]

15. Worthington, M.; Reberg-Horton, S.C.; Brown-Guedira, G.; Jordan, D.; Weisz, R.; Murphy, J.P. Relative contributions of allelopathy and competitive traits to the weed suppressive ability of winter wheat lines against Italian Ryegrass. Crop Sci. 2015, 55, 57-64. [CrossRef]

16. Vandeleur, R.K.; Gill, G.S. The impact of plant breeding on the grain yield and competitive ability of wheat in Australia. Crop Pasture Sci. 2004, 55, 855-861. [CrossRef]

17. Rebetzke, G.J.; Richards, R.A. Genetic improvement of early vigour in wheat. Aust. J. Agri. Res. 1999, 50, 291-302. [CrossRef]

18. Christensen, S. Weed suppression ability of spring barley varieties. Weed Res. 1995, 35, 241-247. [CrossRef]

19. Coleman, R.K.; Gill, G.S.; Rebetzke, G.J. Identification of quantitative trait loci for traits conferring weed competitiveness in wheat (Triticum aestivum L.). Crop Past. Sci. 2001, 52, 1235-1246. [CrossRef]

20. Seavers, G.P.; Wright, K.J. Crop canopy development and structure influence weed suppression. Weed Res. 1999, 39, 319-328. [CrossRef]

21. Zerner, M.C.; Gill, G.S.; Vandeleur, R.K. Effect of height on the competitive ability of wheat with oats. Agron. J. 2008, 100, 1729-1734. [CrossRef]

22. Lemerle, D.; Smith, A.; Verbeek, B.; Koetz, E.; Lockley, P.; Martin, P. Incremental crop tolerance to weeds: A measure for selecting competitive ability in Australian wheats. Euphytica 2006, 149, 85-95. [CrossRef]

23. Watson, P.R.; Derksen, D.A.; Van Acker, R.C. The ability of 29 barley cultivars to compete and withstand competition. Weed Sci. 2006, 54, 783-792. [CrossRef]

24. Upadhyaya, M.K.; Blackshaw, R.E. Non-Chemical Weed Management: Principles, Concepts and Technology; CABI: Oxfordshire, UK, 2007; ISBN 1-84593-290-0.

25. Lemerle, D.; Gill, G.S.; Murphy, C.E.; Walker, S.R.; Cousens, R.D.; Mokhtari, S.; Peltzer, D.J.; Coleman, R.; Luckett, D. Genetic improvement and agronomy for enhanced wheat competitiveness with weeds. Aust. J. Agric. Res. 2001, 152, 527-548. [CrossRef]

26. Van der Meulen, A.; Chauhan, B.S. A review of weed management in wheat using crop competition. Crop Protec. 2017, 95, 38-44. [CrossRef]

27. Matthews, P.; McCaffery, D.; Jenkins, L. Winter Crop Variety Sowing Guide 2015; NSW Department of Primary Industries: Orange, Australia, 2015.

28. Menalled, F.; Schonbeck, M. Manage the weed seed bank—minimize "deposits" and maximize "withdrawals. "Margins 2011, 1, 8.

29. Nkoa, R.; Owen, M.D.K.; Swanton, C.J. Weed abundance, distribution, diversity, and community analyses. Weed Sci. 2015, 63, 64-90. [CrossRef] 
30. Rebetzke, G.; Van Herwaarden, A.; Chenu, K.; Moeller, C.; Biddulph, B.; Richards, R.; Rattey, A. Protocols for experimental plot sampling, handling and processing of cereal experiments: Standardised methods for use in large agronomic, physiological and genetic field studies. PrometheusWiki 2012, 1-46, CSIRO Publishing: Collingwood, Australia. Available online: http://prometheuswiki.publish.csiro.au/tiki-index.php (accessed on 18 October 2014).

31. Mwendwa, J.M.; Brown, W.B.; Wu, H.; Weston, P.A.; Weidenhamer, J.D.; Quinn, J.C.; Weston, L.A. The weed suppressive ability of selected Australian grain crops; case studies from the Riverina region in New South Wales. Crop Prot. 2018, 103, 9-19. [CrossRef]

32. VSN, International. GenStat for Windows, 19th ed.; VSN International: Hemel Hempstead, UK, 2018.

33. Mevik, B.H.; \& Wehrens, R. The pls Package: Principal Component and Partial Least Squares Regression in R. J. Stat. Softw. 2007, 18, 1-23. [CrossRef]

34. Sardana, V.; Mahajan, G.; Jabran, K.; Chauhan, B.S. Role of competition in managing weeds: An introduction to the special issue. Crop Prot. 2017, 95, 1-7. [CrossRef]

35. Akarachantachote, N.; Seree, C.; Kidakan, S. Cutoff threshold of variable importance in projection for variable selection. Int. J. Pure Appl. Math. 2014, 94, 307-322. [CrossRef]

36. Broster, J.C.; Koetz, E.A.; Wu, H. Weed species present in cereal crops in southern New South Wales. In Proceedings of the 18th Australasian weeds conference developing solutions to evolving weed problems, Melbourne, Australia, 8-11 October 2012; pp. 8-11.

37. Wicks, G.A.; Nordquist, P.T.; Baenziger, P.S.; Klein, R.N.; Hammons, R.H.; Watkins, J.E. Winter wheat cultivar characteristics affect annual weed suppression. Weed Tech. 2004, 18, 988-998. [CrossRef]

38. Richards, R.A.; Rebetzke, G.J.; Condon, A.G.; Van Herwaarden, A.F. Breeding opportunities for increasing the efficiency of water use and crop yield in temperate cereals. Crop Sci. 2002, 42, 111-121. [CrossRef] [PubMed]

39. Mwendwa, J.M.; Brown, W.B.; Haque, S.; Heath, G.; Wu, H.; Quinn, J.C.; Weston, L.A. Field evaluation of Australian wheat genotypes for competitive traits and weed suppression. In Proceedings of the 20th Australasian Weeds Conference, Perth, Australia, 11-15 September 2016; pp. 48-53.

40. Korres, N.E.; Froud-Williams, R.J. Effects of winter wheat cultivars and seed rate on the biological characteristics of naturally occurring weed flora. Weed Res. 2002, 42, 417-428. [CrossRef]

41. Maydup, M.L.; Graciano, C.; Guiamet, J.J.; Tambussi, E.A. Analysis of early vigour in twenty modern cultivars of bread wheat (Triticum aestivum L.). Crop Past. Sci. 2013, 63, 987-996. [CrossRef]

42. Austin, R.B. Yield of wheat in the United Kingdom: Recent advances and prospects. Crop Sci. 1999, 39, 1604-1610. [CrossRef]

43. Didon, U.M.E.; Hansson, M.L. Competition between six spring barley (Hordeum vulgare ssp. vulgare L.) cultivars and two weed flora in relation to interception of photosynthetic active radiation. Biological Agri. Horti. 2002, 20, 257-274. [CrossRef]

44. Callaway, M.B. A compendium of crop varietal tolerance to weeds. Am. J. Altern. Agri. 1992, 7, $169-180$. [CrossRef]

45. Jordan, N. Prospects for weed control through crop interference. Ecol. Appl. 1993, 3, 84-91. [CrossRef]

46. Rebetzke, G.; Ingvordsen, C.; Newman, P.; Weston, L.A.; French, B.; Gill, G. Delivering Weed-Competitive, Wheat Breeding Lines to Growers; GRDC Grains Research Update: Wagga Wagga, Australia, 2018; pp. $35-40$.

47. Lazzaro, M.; Costanzo, A.; Farag, D.H.; Bàrberi, P. Grain yield and competitive ability against weeds in modern and heritage common wheat cultivars are differently influenced by sowing density. Ital. J. Agron. 2017, 12. [CrossRef]

(C) 2020 by the authors. Licensee MDPI, Basel, Switzerland. This article is an open access article distributed under the terms and conditions of the Creative Commons Attribution (CC BY) license (http://creativecommons.org/licenses/by/4.0/). 